\title{
Contribution of the Ambulatory Measure of Blood Pressure (AMBP) to the Detection of Hypertension in Type 2 Diabetic Black African
}

\author{
Daniel Amoussou-Guenou ${ }^{1,2 *}$, Armand Wanvoegbe1,3, Anthelme Agbodande ${ }^{2}$, \\ Alihonou Dansou ${ }^{3}$, Yessoufou Tchabi ${ }^{2}$, Yasmine Eyisse ${ }^{2}$, \\ Arnaulde Amoussou-Guenou Fandi ${ }^{4}$, Latif Mousse ${ }^{2}$ \\ ${ }^{1}$ Banque d'insuline, Cotonou, Benin \\ ${ }^{2}$ Polyclinique Atinkanmey, Cotonou, Benin \\ ${ }^{3}$ CHUD-OP, Porto-Novo, Benin \\ ${ }^{4}$ Clinique d'Akpakpa, Cotonou, Benin \\ Email: "danielamousguen@yahoo.fr, wafinarm@yahoo.fr, agbotem@yahoo.fr, bokilson@yahoo.fr, \\ youftchabi@yahoo.fr, minayisse@hotmail.com, aarnaulde@yahoo.fr, victorymousse@yahoo.fr
}

Received 14 May 2015; accepted 30 June 2015; published 3 July 2015

Copyright $@ 2015$ by authors and Scientific Research Publishing Inc.

This work is licensed under the Creative Commons Attribution International License (CC BY). http://creativecommons.org/licenses/by/4.0/

(c) (i) Open Access

\section{Abstract}

This paper is to determine the contribution of the ambulatory measure of blood pressure (AMBP) to the detection of hypertension in type 2 diabetic black African in Benin. Hypertension can stay unknown in diabetic patients. Patients and Methods: We conducted a cross-sectional, prospective, descriptive and analytical study at "Banqued' insuline" of Cotonou, Polyclinique Atinkanmey and CHUD-Ouémé-Plateau. The study took place over a period of 6 months from March 01 to August 30 2014. The study included patients with type 1 or 2 diabetes who agreed to participate in the study and who made ambulatory measure of blood pressure (AMBP). Statistical analysis was done by using the software Excel 2013 and SPSS versus 18.0. Results: Sixty six patients were included. Forty one $(62.1 \%)$ among them were female; sex-ratio was 0.61 . The mean of age was $48.9 \pm 8.8$ years with range from 30 to 68 years. The prevalence of masked hypertension in type 2 diabetics was $37.9 \%(25 / 66)$. Abdominal obesity was the significative factor related to masked high blood pressure (HBP) in the type 2 diabetics $(p=0.005)$. Among diabetic with masked hypertension, 14 (56\%) had "no dipper" profile and $11(44 \%)$ had "dipper" profile. Conclusion: The ambulatory measure of blood pressure (AMBP) may take an important place in the detection of Hypertension in black type 2 diabetic subjects.

"Corresponding author.

How to cite this paper: Amoussou-Guenou, D., et al. (2015) Contribution of the Ambulatory Measure of Blood Pressure (AMBP) to the Detection of Hypertension in Type 2 Diabetic Black African. Journal of Diabetes Mellitus, 5, 141-145. 


\section{Keywords}

\section{Diabetes Mellitus, Masked Hypertension, AMBP}

\section{Introduction}

High blood pressure (HBP) represents a very common comorbidity, which affects $20 \%$ to $60 \%$ of diabetic subjects in the world [1]. Its detection and treatment in diabetic are some more effective measures to prevent complications [2] [3]. The usual method of detection of HBP in our african context is punctual measure of blood pressure. This method of detection suffers from bias linked with the lability of blood pressure numbers. Bias may be avoided by using the ambulatory measure of blood pressure (AMBP); punctual measure of BP is less effective than self measure or AMBP [4]. Thus, the AMBP reveals hypertension due to doctor, masked hypertension and nocturnal hypertension and is better related to cardiovascular complications and target organs' damage [5] [6]. Moreover, it benefits from a better prediction of cardiovascular risk in suffering from hypertension cured or not [6] to identify cardiovascular high risk in population permit to opposite an effective prevention. The aim of this study was to determine the contribution of the ambulatory measure of blood pressure (AMBP) to the detection of hypertension in type 2 diabetic black African in Benin.

\section{Methods}

We conducted a cross-sectional, prospective, descriptive and analytical study. It took place over a period of 6 months from March to August 2014. The study was conducted in two major cities namely Porto-Novo and Cotonou and specifically: the Departmental Hospital of Oueme-Plateau (CHUD-OP) in Porto-Novo, the center for screening and monitoring of diabetes "Banque d'insuline" (BI) of Cotonou and Polyclinic Atinkanmey (PA) in Cotonou.

The study population consisted of normotensive type 2 diabetes, regardless of age or sex, followed by diabetes consultation in these three centers during the study period who agreed to participate in the study and who made ambulatory measure of blood pressure (AMBP).

The blood pressure was taken in all diabetic subjects with an electronic OMRON blood pressure monitor according to the British hypertension society criterions at the two arms after five minutes rest in supine position and after three minutes rest in orthostatic position. Informed consent of the respondents was obtained after explaining the objectives of our work.

The BP pressure measure's conditions were the same in all the patients.

The normotensive subjects at investigation were selected to realize an ambulatory blood pressure measure at the required center. Measures are done every 15 minutes during day and every 30 minutes at night. Reading and interpretation of the results were done by the same cardiologist of the center. The tension is Dipper profile when it falls from $10 \%$ to $20 \%$ during night comparing to daily record and the tension is no Dipper when it does not fall from $10 \%$ to $20 \%$ during the night.

Data were entered and analyzed using SPP 18.0 software. Categorical variables were expressed as a percentage and quantitative variables averaged together with a standard deviation. The association between hypertension and investigated factors was studied by calculating the odd ratio (OR) or relative risk (RR) with $95 \%$ confidence interval.

\section{Results}

During the period of study, the AMBP has been realized in sixty six (66) "normotensive" diabetic patients by conventional measure method.

\subsection{Characteristics of the Study Population}

Female were predominant $(62.1 \%)$ with a sex-ratio $=0.6$.

The average age of the patients from the sub-group was $48.9 \pm 8.8$ years with extremes from 30 to 68 ans. Patients in majority $(77.3 \%)$ had less than 55 years. Sixty-three $(95.5 \%)$ from 66 patients lived in urban medium. There is predominance $(48.5 \%)$ of customers. The majority $(87.9 \%)$ of patients from that sub-group lived in 
couple.

The majority of our patients $(72.2 \%)$ had uncontrolled diabetes (glycated hemoglobin $\geq 7 \%$ ).

\subsection{Prevalence of Masked Hypertension}

Twenty-five diabetic patients were masked hypertension suffering with a prevalence of $37.9 \%$ (see Table 1 ).

\subsection{Risk Factors (Table 2)}

\subsubsection{Gender}

Gender would not affect the occurrence of unknown hypertension through punctual measure of BP in type 2 diabetics $(\mathrm{p}=0.186)$.

\subsubsection{Age}

Age would not affect the occurrence of unknown hypertension through punctual measure of BP in type 2 diabetics $(p=0.271)$. The prevalence of masked hypertension by conventional measure of BP in type 2 diabetics aged less than 55 years was $33.3 \%$. More than 55 years, it was $53.3 \%$.

Table 1. Prevalence of masked HBP in diabetics.

\begin{tabular}{ccc}
\hline Tensional Profile & Number & Percentage \\
\hline HBP & 25 & $\mathbf{3 7 . 9 \%}$ \\
Non HBP & 41 & $62.1 \%$ \\
Total & 66 & $100 \%$ \\
\hline
\end{tabular}

Table 2. Summary of relation between masked HBP and investigated factors.

\begin{tabular}{|c|c|c|c|c|c|c|}
\hline \multirow{2}{*}{\multicolumn{2}{|c|}{ Factors }} & \multicolumn{2}{|c|}{ HBP } & \multirow{2}{*}{$\mathrm{OR} / \mathrm{RR}$} & \multirow{2}{*}{ CI } & \multirow{2}{*}{$\mathrm{p}$} \\
\hline & & Present & Absent & & & \\
\hline \multirow{2}{*}{ Sex } & Male & 12 & 13 & \multirow{2}{*}{1.9} & \multirow{2}{*}{$0.7-5.5$} & \multirow{2}{*}{0.186} \\
\hline & Female & 13 & 28 & & & \\
\hline \multirow{2}{*}{ Age } & $<55$ years & 17 & 34 & \multirow{2}{*}{0.4} & \multirow{2}{*}{$0.1-1.4$} & \multirow{2}{*}{0.271} \\
\hline & $\geq 55$ years & 08 & 07 & & & \\
\hline \multirow{3}{*}{$\begin{array}{c}\text { Abdominal } \\
\text { obesity }\end{array}$} & Present & 25 & 30 & \multirow[b]{2}{*}{-} & \multirow{3}{*}{-} & \multirow{3}{*}{$\underline{0.005}$} \\
\hline & Absent & 00 & 11 & & & \\
\hline & $<25$ & 02 & 12 & 1 & & \\
\hline \multirow[t]{2}{*}{ Body mass (BMI) } & $25-29.99$ & 13 & 17 & 4.6 & $0.9-24.1$ & 0.089 \\
\hline & $\geq 30$ & 10 & 12 & 5.0 & $0.9-27.8$ & 0.076 \\
\hline \multirow{2}{*}{ Dyslipidemia } & Present & 08 & 09 & \multirow{2}{*}{1.5} & \multirow{2}{*}{$0.4-5.9$} & \multirow{2}{*}{$0.57 \mathrm{c}$} \\
\hline & Absent & 06 & 10 & & & \\
\hline \multirow{3}{*}{$\begin{array}{c}\text { Duration of } \\
\text { diabetes }\end{array}$} & $<10$ years & 19 & 29 & 1 & & \\
\hline & $10-20$ years & 06 & 10 & $0.9^{*}$ & $0.3-2.9$ & 0.882 \\
\hline & $>20$ years & 00 & 02 & $0.6^{*}$ & $0.5-0.7$ & 0.519 \\
\hline \multirow{2}{*}{$\begin{array}{l}\text { Micro albuminuria } \\
24 \mathrm{~h}\end{array}$} & Present & 05 & 06 & \multirow{2}{*}{0.5} & \multirow{2}{*}{$0.1-2.7$} & \multirow{2}{*}{0.453} \\
\hline & Absent & 05 & 11 & & & \\
\hline \multirow{2}{*}{$\begin{array}{l}\text { Diabetes } \\
\text { imbalance }\end{array}$} & $\mathrm{HbA} 1 \mathrm{c} \geq 7$ & 12 & 14 & \multirow{2}{*}{1.3} & \multirow{2}{*}{$0.3-5.7$} & \multirow{2}{*}{0.967} \\
\hline & $\mathrm{HbA} 1 \mathrm{c}<7$ & 04 & 06 & & & \\
\hline
\end{tabular}

HbA1c: glycated hemoglobin; OR: odd ratio; RR: relative risk CI: confidence interval. 


\subsubsection{Abdominal Obesity}

Abdominal obesity has significant influence on incidence of unknown HBP by punctual measure of BP in type 2 diabetic $(\mathrm{p}=0.005)$. All the patients who had hypertension with AMBP had abdominal obesity.

\subsubsection{Dyslipidemia}

Dyslipidemia would not influence the incidence of HBP at AMBP in type 2 diabetics $(p=0.579)$.

\subsubsection{Duration of Diabetes}

Duration of diabetes would not influence the incidence of HBP at AMBP in type 2 diabetics $(p=0.519)$.

\subsubsection{Imbalance of Diabetes}

Imbalance of diabetes would not influence the occurrence of HBP at AMBP in type 2 diabetics $(p=0.967)$.

\subsection{Profile of HBP at AMBP}

From twenty-five (25) diabetics with hypertension at AMBP, 14 (56\%) had a "no Dipper profile" (see Table 3).

Table 3. Repartition of hypertensive patients at AMBP according to "dipper profile" and "no dipper" HBP.

\begin{tabular}{ccc}
\hline Profile & Number & Percentage \\
\hline Dipper & 11 & $44 \%$ \\
No dipper & 14 & $\mathbf{5 6 \%}$ \\
Total & 25 & $100 \%$ \\
\hline
\end{tabular}

\section{Discussion}

The prevalence of masked HBP varies in accordance with studies between 10\% and 40\% [7] among investigated populations.

The prevalence of masked HBP in type 2 diabetics in our study was $37.9 \%$. The result is opposable to one of Tanguy et al. [8]. They reported that masked HBP is important, till more than $40 \%$ in "normotensive" diabetics.

Lower frequencies have been noticed in general population: 11\% by Sheaf [9] in France; $13.8 \%$ by Harvest [10] in Italy and 23\% in Japan [11].

Gender was not an associated factor to masked hypertension in our study. At opposite, SHEAF's study [9] has shown that gender (male) is an associated factor to masked hypertension.

Age was not an associated factor to masked hypertension in our study. The same finding was noticed in Italy by Palatini et al. [10].

We have identified abdominal obesity as an associated factor of masked hypertension in type 2 diabetics ( $\mathrm{p}=$ 0.005). It could be related to metabolic syndrome that has increasing incidence in populations. For this reason, detection of HBP by AMBP among patients with metabolic syndrome would be systematic.

Regarding the results of our study, the BMI was not as an associated factor of masked hypertension in type 2 diabetics. Some authors, at opposite [7] [9] [12] demonstrated that BMI was a predictive factor of masked hypertension in general population, particularly those with BMI $\geq 25 \mathrm{Kg} / \mathrm{m}^{2}$.

Other factors (dyslipidemia, circadian micro albuminuria, imbalance of diabetes and duration of diabetes) in our study were not associated factor of masked hypertension in type 2 diabetics.

Moreover, $56 \%$ of masked hypertensive had a "no dipper" profile and $44 \%$ a "dipper" profile in our study. This fact is opposable to the one of Heggie et al. [13] who reported a frequency around $50 \%$ of no dipper profile in type 2 diabetics with hypertension. Korkmaz et al. in 2012 (Turquey) [14] showed a higher frequency (72\%) in de type 2 diabetics.

\section{Conclusion}

The conventional measure of BP in consultation is not enough for the detection of HBP in diabetics particularly 
in obese diabetics subjects. Our study found a $37.9 \%$ prevalence of masked hypertension among our type 2 diabetics. All the masked hypertensive diabetic subjects had an abdominal obesity, so that the systematic realization of AMBP in obese "normotensive" diabetics was mandatory.

\section{References}

[1] Racine, N. (2003) High Blood Pressure in Diabetic Patients: How to Evaluate and Treat? Le Clinicien, 95-102.

[2] Campbell, N.R.C., Gilbert, R.E., Leiter, L.A., et al. (2011) Hypertension in Patients with Type 2 Diabetes. Update on Pharmacological Treatment. Canadian Family Physician, 57, e347-e53.

[3] Ben-Hamouda-Chihaoui, M., Kanoun, F., Ftouhi, B., et al. (2011) Evaluation of Blood Pressure Control by Ambulatory Blood Pressure Monitoring and Study of Factors Associated with Poor Blood Pressure Control in 300 Treated Hypertensive Type 2 Diabetic Patients. Annales De Cardiologie Et D Angeiologie, 60, 71-76.

[4] Faouzi, K., Nefissa, B.A., Salma, I., et al. (2010) Appreciation of the BP Profile by Ambulatory Measure of Blood Pressure in Hypertensive Diabetics Treated. La Tunisie Médicale, 88, 885-889.

[5] Hernandez, A., Rodriguez, E.G., Ballan, B.K., et al. (2012) The AMBP: Extension of the Physical Examination Done Well? Revue Médicale Suisse, 8, 1702-1708.

[6] Working Group for the Management of Hypertension of the European Society of Hypertension (ESH) and European Society of Cardiology (ESC) (2007) Recommendations ESH 2007 for the Treatment of High Blood Pressure. Journal of Hypertension, 25, 1105-1187.

[7] Vaisse, B. (2006) Masked Hypertension. Réalités cardiologiques, 1, 1-4.

[8] Tanguy, B and Aboyans, V. (2012) The Management of Hypertensive Diabetic Patients. Revues Générales Diabétologie, 49-53.

[9] Bobrie, G., Chatellier, G., Genes, N., et al. (2004) Cardiovascular Prognosis of "Masked Hypertension" Detected by Blood Pressure Self-Measurement in Elderly Treated Hypertensive Patients. Journal of the American Medical Association, 291, 1342-1349. http://dx.doi.org/10.1001/jama.291.11.1342

[10] Palatini, P., Winnicki, M., Santonastaso, M., et al. (2004) Prevalence and Clinical Significance of Isolated Ambulatory Hypertension in Young Subjects Screened for Stage 1 Hypertension. Hypertension, 44, 170-174. http://dx.doi.org/10.1161/01.HYP.0000135250.57004.19

[11] Ohkubo, T., Kikuya, M., Metoki, H., et al. (2005) Prognosis of "Masked" Hypertension and "White-Coat" Hypertension Detected by 24-h Ambulatory Blood Pressure Monitoring. 10-Year Follow-Up from the Ohasama Study. Journal of the American College of Cardiology, 46, 508-515. http://dx.doi.org/10.1016/j.jacc.2005.03.070

[12] Bangalore, S., Kumar, S., Lobach, I., et al. (2011) Blood Pressure Targets in Subjects with Type 2 Diabetes Mellitus/ Impaired Fasting Glucose : Observations from Traditional and Bayesian Random-Effects Meta-Analyses of Randomized Trials. Circulation, 123, 799-810. http://dx.doi.org/10.1161/circulationaha.110.016337

[13] Heggie, A.J., Adamson, K.A., Marioni, R.E., et al. (2008) Is Non-Dipping of Nocturnal Blood Pressure in Type 2 Diabetes Associated With Increased Incidence of Microalbuminuria? British Journal of Diabetes and Vascular Disease, 8 , 136-139.

[14] Korkmaz, S., Yilmaz, A., Yildiz, G., et al. (2012) Relationship between Homocysteine and Non-Dipper Pattern in Patients with Type 2 Diabetes Mellitus. Arquivos Brasileiros de Endocrinologia. Metabologia, 56, 285-290. 